\title{
Two novel frameshift mutations in NKX2.5 result in novel features including visceral inversus and sinus venosus type ASD
}

\author{
Y Watanabe, D W Benson, S Yano, T Akagi, M Yoshino, J C Murray
}

J Med Genet 2002;39:807-811

$\mathrm{R}$ ecently, heterozygous mutations of human NKX2.5 were identified in patients with congenital heart disease. ${ }^{12}$ The most common phenotypes were progressive atrioventricular conduction delays (AV block) and secundum atrial septal defect (ASD), but other anatomical abnormalities, such as ventricular septal defect, tetralogy of Fallot, or tricuspid valve abnormalities, including Ebstein's anomaly, and progressive left ventricular failure, were also reported. These findings strongly suggest that $N K X 2.5$ is important in the later stages of heart development and maturation in addition to its role in cardiac progenitor commitment and patterning in the developing heart.

To characterise further the genotype-phenotype correlation of NKX2.5 mutations, we used NKX2.5 as a candidate gene in two kindreds where subjects in multiple generations had congenital heart disease and AV block. In this report, we describe phenotypes in two families with novel frameshift mutations in NKX2.5. The findings suggest an expanded population of subjects who could now be examined for mutations within this transcription factor and its upstream and downstream regulatory elements.

\section{MATERIALS AND METHODS Subjects}

All studies were carried out in accordance with the institutional guidelines for human research. Subjects were evaluated by history, review of medical records, physical examination, 12 lead electrocardiogram (ECG), and two dimensional transthoracic echocardiography with colour flow Doppler. Cardiac catheterisation, abdominal echography, and/or cardiac surgery have been performed in some subjects.

Following the methods of Benson et al, ${ }^{1}$ the products, including all coding regions and intervening intron of NKX2.5, were amplified with the primers ( $1 \mathrm{~F}$ and $4 \mathrm{R}$ ) in a single polymerase chain reaction (PCR), using standard conditions and concentrations of reagents. Products were analysed on standard $1 \%$ agarose gels and stained with ethidium bromide. Sequencing primers used were previously designed for specific region sequencing ${ }^{1}$ and carried out on the Applied Biosystems DNA Sequencing system (Model 373 or 377). For family 1, the deletion mutation was originally identified as two apparently different sequences overlapping at the deletion point in direct sequencing analysis. To clarify the actual sequence change on the mutant allele, the PCR products were amplified with IF and $1 \mathrm{R}$, cloned by a TA cloning kit, and sequenced. Four individual clones were sequenced with two for the wild type and two for the mutant allele identified. To confirm 215-221del, sequence length differences were determined using primers oywAl7 (5'-CTAAACCTGGAACAGCAGCA-3') and oywAl8 (5'-TTTTCGGCTCTAGGGTCCTT-3'), designed at the flanking region to the deletion mutation in exon 1. A BssHII site was abolished by 223-224del allowing independent confirmation of this deletion mutation (not shown).

\section{Key points}

- Mutations in NKX2.5 have been found in subjects with atrioventricular (AV) node conduction failure and/or structural cardiac anomalies, especially secundum type atrial septal defect (ASD).

- We describe here the phenotypes in two families with novel frameshift mutations in NKX2.5. The mutations cosegregated with ASD and/or AV conductive abnormalities as an autosomal dominant trait.

- In one family, the proband had visceral inversus, polysplenia, and a symmetrical liver as well as ASD. The older sister of the proband was diagnosed with atrial fibrillation (AF) as the only phenotypic expression of the gene mutation.

- This is the first report in humans to show the NKX2.5 gene involved in the regulation of the left-right axis path and as a cause of isolated AF. In addition, a sinus venosus type ASD was identified, which is also a novel phenotype for a NKX2.5 mutation.

\section{RESULTS}

Family 1

A 7 bp (AGCTGGG) deletion in exon 1 at nucleotide +215 from the translation starting point of the NKX2.5 gene resulting in a frameshift from amino acid 72 of downstream codons was identified in five members of family 1 (fig lA, B). The deletion arises in amino acid 72; the resulting frameshift predicts a truncated protein (172 amino acids) without a homeodomain.

\section{Family 2}

A 2 bp (CG) deletion in exon 1 at nucleotide +223 from translation starting point of the $N K X 2.5$ was identified in affected family members but not in unaffected family members (fig 2A, B). The deletion frameshift arises in amino acid 75 in exon 1 , which would predict a truncated protein (105 amino acids) without a homeodomain

Neither mutation was observed in unaffected family members or 162 chromosomes from 81 unaffected, unrelated controls drawn from subjects of the three different geographical origins (39 white, 31 Asian, 11 African-American) relevant to family 1 (Asian) or family 2 (white).

\section{Family 1}

215-22 1 del was identified in five members of family l (fig lA). Surgical closure of the atrial septum defect (ASD) was performed in four genotype positive subjects in family l. Anatomical details of the ASD were not specified in one case, but sinus venosus ASD was identified in II.1, III.5, and III.7. In 

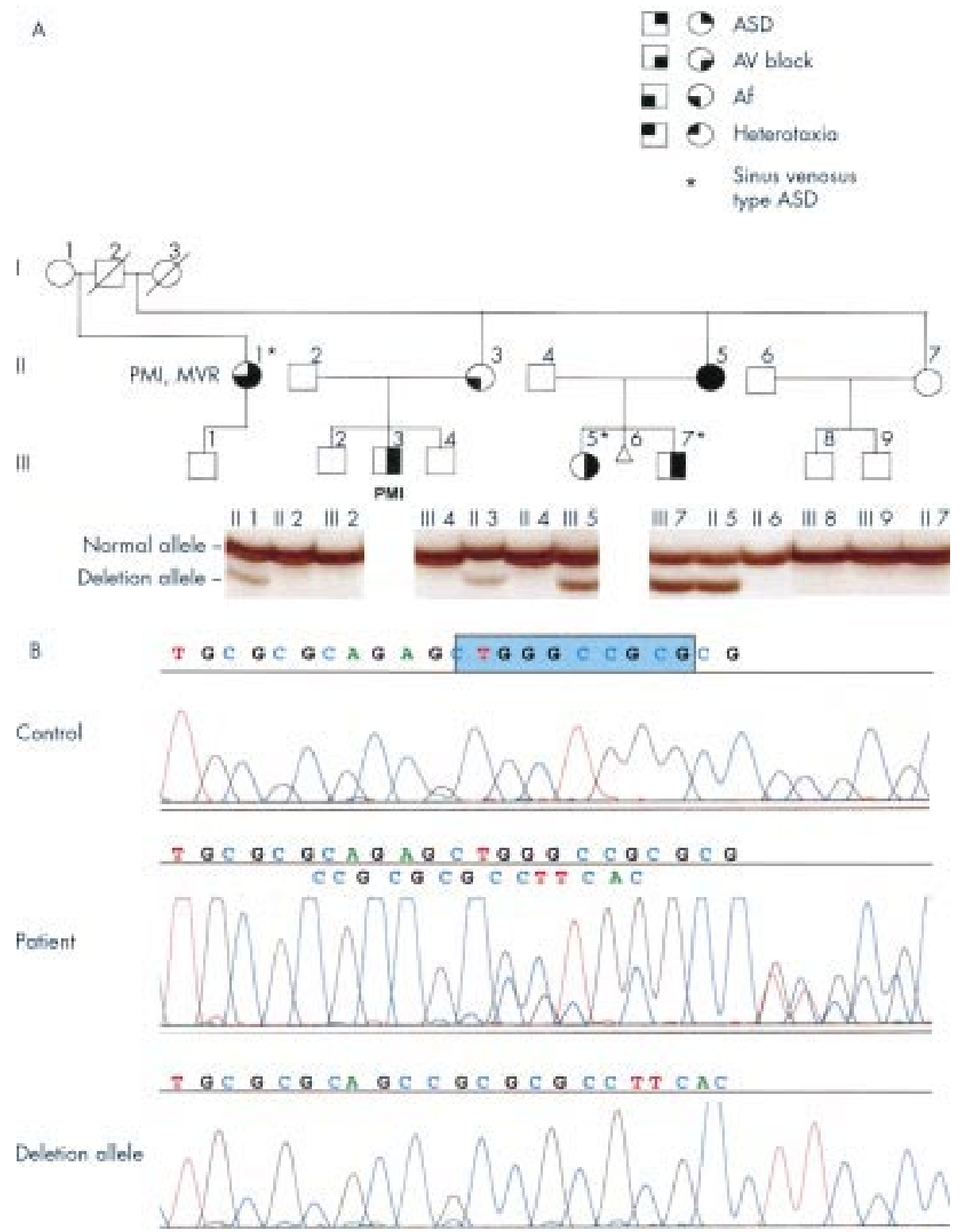

Figure 1 (A) The segregation of NKX2.5 mutation in family 1. PCR products were amplified using primers oywA17/oywA18, which were designed at the flanking region to the deletion mutation. The products were run on a $6 \%$ sequencing gel. The deletion allele cosegregated with ASD and/or conduction abnormality. II.2, III.5, and III.7 had sinus venosus type ASD. None of the unaffected members in this family had the deletion allele. DNA from I. 1, I.2, I.3, III. 1, and III.3 was not available for study. (B) Sequences of NKX2.5 mutation in family 1. The middle sequence shows the heterozygous mutation in a patient and compares it with the top and bottom sequences, which are from a control and a subcloned DNA sequence of a patient, respectively. Highlighted 7 bp nucleotides are deleted in the affected allele.

addition, II. 1 had a double orifice mitral valve and underwent mitral valve replacement at the time of ASD surgery. ECG evidence of AV block was confirmed in four subjects; in two subjects this manifested as Mobitz type 1 second degree block and was associated with atrial fibrillation. In II.5, atrial fibrillation was first noted 28 years after ASD surgery, but in II.3 atrial fibrillation, first noted at age 46 years, is the sole manifestation of cardiac disease (fig 3). Additionally, II.5 was diagnosed with polysplenia and a midline, symmetrical liver by computed tomography; malrotation was diagnosed by a barium $x$ ray study that showed the ascending colon and caecum were shifted to the midline and forwards with the small intestine on the left. The positions of the lungs, the heart, and the stomach were normal as were the number of right and left lung lobes. No other family member had evidence of heterotaxy. III.7 had undergone surgery for pyloric stenosis. Three family members with suspected heart disease could not be genotyped. I.2 died unexpectedly aged 49 years. III.1 had unspecified congenital heart disease and II.3 underwent ASD closure and pacemaker implantation in childhood.

\section{Family 2}

223-224del was identified in four members (II.2, III.1, III.2, and III.3) of family 2 (fig 2A). Surgical closure of a secundum ASD was performed in three members of family 2 (II.2, III.1, and III.2). All three subjects had ECG evidence of first or second degree AV block. In III.3, first degree AV block was the only manifestation of heart disease (fig 3). I.2 could not be genotyped although she had a history of surgical closure of ASD and pacemaker implantation for AV block.

\section{DISCUSSION}

Deletion frameshift mutations of NKX2.5 are reported here for the first time. Human DNA sequences involved in deletion 
A
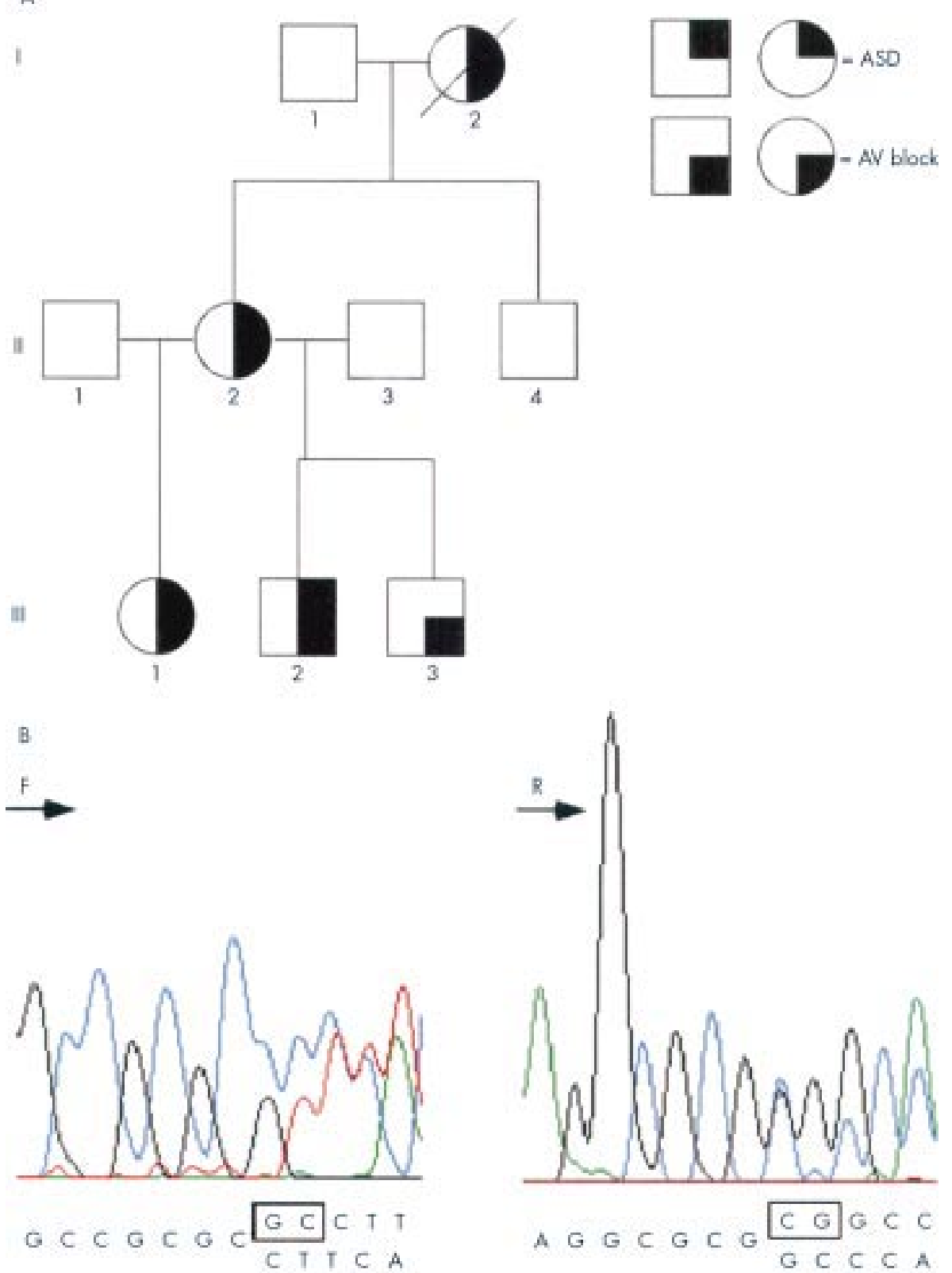

Figure 2 (A) The segregation of NKX2.5 mutation in family 2. (B) Sequences of the NKX2.5 mutation in family 2. The left chromatogram shows the sequence of the forward direction, and the right chromatogram shows the sequence of the reverse direction. Two nucleotides, GC, deleted in the mutation chromosome, are shown in the square in the sequence of the wild type chromosome. Following the deletion point, two apparently different sequences overlap in each direction.

events may contain a $\mathrm{TG}(\mathrm{A} / \mathrm{G})(\mathrm{A} / \mathrm{G})(\mathrm{G} / \mathrm{T})(\mathrm{A} / \mathrm{C})$ consensus sequence, are GC rich, and are often associated with palindromic sequences. ${ }^{3}$ The region covering the two deletion mutations described here is highly GC rich (75-85\%) and for nucleotides 218-223, TGGGCC is similar to the sequences with the deletion hotspot consensus-like motif. Nucleotide 198-221 (CCCAGAGCTGCGCGCAGAGCTGGG) is a quasipalindrome, though the exact location of the deleted bases is not predictable from the location of inverted repeats. CG repeats are also found from nucleotide 223 to nucleotide 228 , which may cause slippage mispairing leading to 223-224delCG. These findings may suggest the existence of a deletion hotspot for $N K X 2.5$.

Nkx2.5 plays an important role in cardiac development and maintenance of AV node function. ${ }^{4}$ The primary phenotypes with $N K X 2.5$ point mutations identified in exon 2 include AV block with or without ASD. ${ }^{12}$ Even though $68 \%$ of genotype positive subjects had secundum ASDs, additional cardiac defects, including tetralogy of Fallot (TOF), ventricular septal defect (VSD), pulmonary atresia (PA), subvalvular aortic stenosis, and left ventricular hypertrophy (LVH), were also reported in the affected subjects (table 1 ). Since a splicing mutation at IVSIDS +1 , G-T produced no protein in the transfected cells, and the patient with this mutation had only AV block, Kasahara et $a l^{5}$ hypothesised that the null allele might cause AV conduction delay and hypomorphic mutant proteins might cause other cardiac anatomical anomalies as additional dominant negative effects. ${ }^{5}$ II.3 of family 1 with $215-221$ del had solely AF, and the other affected family members had both cardiac structural anomalies and an AV conduction abnormality. The mutation reported here probably results in a truncated non-functional protein without the homeodomain. 

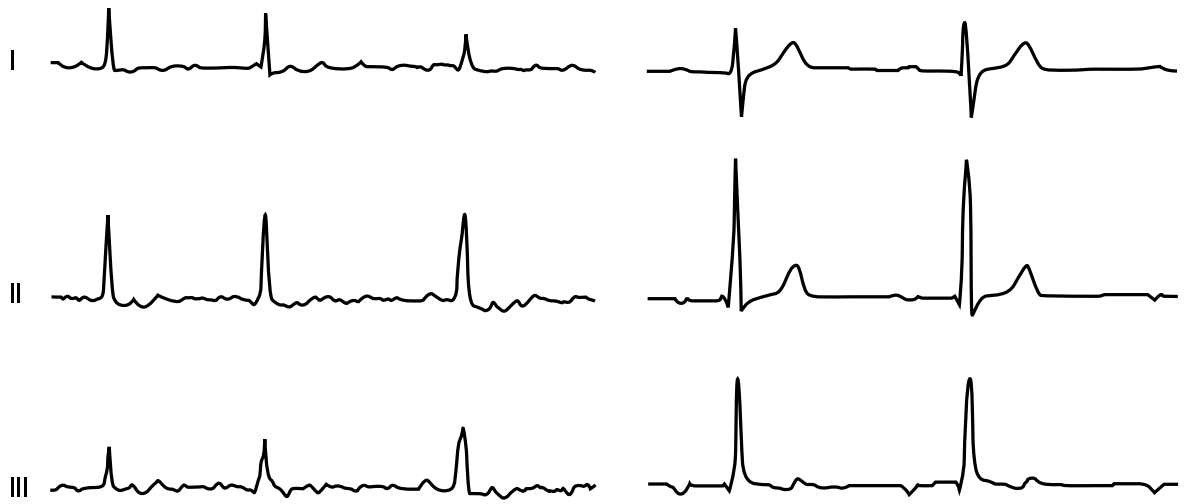

Figure 3 In II. 3 in family 1, atrial fibrillation is the sole manifestation of cardiac disease. III. 3 in family 2 had first degree AV block as the only manifestation of heart disease.

At least five out of 45 subjects with mutations in NKX2.5 lacked congenital cardiac structural anomalies and had only atrioventricular node dysfunction. Benson et al reported a family BEF (C565G, Arg 189Gly) in which three adult members who had never had congenital heart disease surgery were identified as having a variety of arrhythmias, including atrial fibrillation. In the same families observed with only conduction failures, patients with cardiac anatomical anomalies were found as well. Thus, it is difficult to outline any significant genotype-phenotype correlations.

An unusual phenotype in the first family with 215-221del was visceral inversus. In Xenopus, Nkx2.5 expression and foregut looping are strongly coupled and may be generated independently in response to a common local signal. ${ }^{6}$ However, polysplenia and a midline, symmetrical liver associated with 215-221 del may suggest that an inappropriate signal of NKX2.5 itself can affect foregut looping. Since in early mouse development (12.5 dpc) Nkx2.5 is transiently expressed in spleen, liver, and "distal stomach", but not colon or distal small intestine, ${ }^{7}$ the mechanism of malrotation of the intestine is unclear. The observation of the Nkx2.5 effects in Xenopus regarding laterality of foregut looping independent from heart looping is consistent with the findings seen in II.5 in family $1 .{ }^{6}$
In humans, a few genes have been reported related to situs abnormalities, which included LEFTY $A^{8}$ and ZIC3. ${ }^{9}$ The lack of lefty- 1 in the mouse resulted in bilateral expression of nodal, lefty-2, and Pitx $2 .{ }^{10}$ Nodal and Lefty are expressed asymmetrically, and asymmetrical expression of Pitx 2 in morphogenesis induced by these signalling molecules mediates both the initiation and maintenance of L-R asymmetrical expression. In mouse, frog, and zebrafish embryos, Pitx2 is known to be asymmetrically expressed in the left lateral plate mesoderm. In mouse and frog embryos, Pitx 2 is also known to be expressed in the tubular heart and early gut tube, and continues when these organs undergo asymmetrical looping. ${ }^{11}$ An $N k \times 2.5$ binding site in Pitx 2 was recently reported to be essential for the maintenance of asymmetrical expression of Pitx2. ${ }^{12}$ The predicted truncated NKX2.5 protein caused by the deletion mutations might abolish some specific sites for interaction with PITX2 or other genes involved in cardiac morphogenesis or L-R axis formation.

The sinus venosus type ASD seen in II.1, III.4, and III.5 in family 1 is a rare type of defect and has not been previously reported as a phenotype of NKX2.5 mutations. The sinus venosus type ASD is thought to be the result of incomplete absorption of the sinus venosus into the right atrium and/or abnormal development of the septum secundum, while the

Table 1 Phenotype-genotype correlation

\begin{tabular}{|c|c|c|c|c|c|c|c|c|c|c|c|c|}
\hline \multirow[b]{2}{*}{ Mutation } & \multirow[b]{2}{*}{ Site } & \multirow{2}{*}{$\begin{array}{l}\text { No of } \\
\text { genotype } \\
\text { positive }\end{array}$} & \multirow[b]{2}{*}{$\begin{array}{l}\text { AV } \\
\text { block }\end{array}$} & \multicolumn{3}{|l|}{ ASD } & \multicolumn{2}{|l|}{ VSD } & \multirow{2}{*}{$\begin{array}{l}\text { TV } \\
\text { abnorm- } \\
\text { ality }\end{array}$} & \multirow{2}{*}{$\begin{array}{l}\text { MV } \\
\text { abnorm- } \\
\text { ality }\end{array}$} & \multirow[b]{2}{*}{$\begin{array}{l}\text { Hetero- } \\
\text { taxia }\end{array}$} & \multirow[b]{2}{*}{ Reference } \\
\hline & & & & $\begin{array}{l}\text { Sinus } \\
\text { venosus }\end{array}$ & Secundum & Unknown & $\begin{array}{l}\text { Cono- } \\
\text { ventricular }\end{array}$ & Muscular & & & & \\
\hline $\begin{array}{l}\text { 215-221- } \\
\text { delAGCTGGG* }\end{array}$ & $\begin{array}{l}5^{\prime} \text { coding } \\
\text { region }\end{array}$ & 5 & 4 & 3 & 1 & 2 & 0 & 0 & 0 & 1 & 1 & This report \\
\hline C182T, Arg25Cys & $\begin{array}{l}5^{\prime} \text { coding } \\
\text { region }\end{array}$ & 1 & 1 & 0 & 0 & 0 & 1 (TOF) & 0 & 0 & 0 & 0 & 1 \\
\hline IVSIDS+1, G-T & Splice site & 1 & 1 & 0 & 0 & 0 & 0 & 0 & 0 & 0 & 0 & 1 \\
\hline C554, Gln 149ter & Homeodomain & 6 & 5 & 0 & 4 & 0 & 1 (TOF) & 2 & 0 & 0 & 0 & 1 \\
\hline C618T, Gln 170ter & Homeodomain & 4 & 4 & 0 & 2 & 0 & 0 & 0 & 0 & 0 & 0 & 2 \\
\hline C642T, Thr 178Met & Homeodomain & 12 & 12 & 0 & 11 & 0 & 0 & 0 & 0 & 0 & 0 & 2 \\
\hline C673A, Asn 188Lys & Homeodomain & 5 & 5 & 0 & 5 & 0 & 0 & 0 & $3 \dagger$ & 0 & 0 & 1 \\
\hline C674G, Arg 189 Gly & Homeodomain & 5 & 5 & 0 & 4 & 0 & 0 & 0 & 1 & 0 & 0 & 1 \\
\hline A681G, Tyr191Cys & Homeodomain & 1 & 1 & 0 & 1 & 0 & 1 & 0 & 0 & 0 & 0 & 1 \\
\hline C701T, Gln 198ter & $\begin{array}{l}3^{\prime} \text { coding } \\
\text { region }\end{array}$ & 4 & 4 & 0 & 3 & 1 & 0 & 0 & 0 & $0 \ddagger$ & 0 & $\begin{array}{l}\text { 2, Hosoda } \\
\text { et al (1999) }\end{array}$ \\
\hline C886A, Tyr259ter & $\begin{array}{l}3^{\prime} \text { coding } \\
\text { region }\end{array}$ & 7 & 7 & 0 & 6 & 0 & 2 & 1 & 0 & 0 & 0 & 1 \\
\hline
\end{tabular}

*The numbering 215-221 in the deletion mutation corresponds to 324-330 in the numbering system by Benson et al. ${ }^{1}$

†Ebstein's anomaly.

$\ddagger$ One of the affected members, whose genotype was not available, had mitral valve fenestrations.

This table was modified from the table by Benson et al.' 
secundum type ASD results from abnormal resorption of the septum primum and/or defective development of the septum secundum. ${ }^{13}$ II. 1 in family 1 had a double orifice mitral valve. Abnormal tricuspid and mitral valve morphology and semilunar valvular dysmorphogenesis have been reported in humans $^{1}$ and in heterozygous mutant mice, respectively. ${ }^{14}$ Diversity in phenotypes seen in patients with NKX2.5 mutations may imply a modifier gene of NKX 2.5. ${ }^{14}$ However, it is also possible that the $7 \mathrm{bp}$ deletion mutation may abolish some specific site for interaction with other genes, including genes involved in cardiac morphogenesis or L-R axis formation.

In summary, two novel deletion mutations in exon 1 of NKX2.5 are reported. 223-224del results in a classical phenotype with secundum ASD with or without AV block, and 215-221del generates two novel phenotypes, heterotaxia and sinus venosus type ASD. While it is likely that these effects are secondary to haploinsufficiency, it is also possible that the truncated protein is exerting a dominant negative effect based on critical regulatory elements located in the N-terminal portion of the protein, especially in 223-224del. Searches for familial mutations in the NKX2.5 gene should now include those subjects with visceral inversus, sinus venosus type ASDs, or atrial fibrillation. Identifying mutations in NKX2.5 can have a significant impact on genetic counselling in the affected families.

\section{ACKNOWLEDGEMENTS}

We acknowledge Dr Kanoko Hashino for useful discussion and suggestions and Lora Muilenburg for administrative support. We thank our clinical colleagues Dr Kotaro Ichikawa, Dr Hideaki Sakai, Dr Kinji Soga, and Dr Anirban Banerjee. We are also grateful to the family members for their participation in this study. This work was supported by grants P60 DE13076 (JCM), R01 DE08559 (JCM), DK25295 (core grant), HL61006 (DWB), HL/HD04300 (DWB), and by 09-77-0-591 (the Ministry of Education, Japan, YW).

Electronic database information. Accession number and URL for data in this article are as follows. Online Mendelian Inheritance in Man (OMIM), http://www.ncbi.nlm.nih.gov/entrez/query.fcgi?db=OMIM (for NKX2.5 MIM 600584).

\section{Authors' affiliations}

Y Watanabe, J C Murray, Department of Pediatrics, University of lowa, lowa City, IA, USA

Y Watanabe, S Yano, T Akagi, M Yoshino, Department of Pediatrics and Child Health, Kurume University School of Medicine, Fukuoka, Japan D W Benson, Children's Hospital Medical Center of Cincinnati, Cardiology Department, Location C, 4th Floor, 3333 Burnet Avenue, Cincinnati, OH, USA
S Yano, Medical Genetics, Department of Pediatrics, Children's Hospital Los Angeles, University of Southern California, Los Angeles, CA, USA

Correspondence to: Dr J C Murray, Department of Pediatrics, The University of lowa, 140 EMRB lowa City, IA 52242, USA

jeff-murray@uiowa.edu

\section{REFERENCES}

1 Benson DW, Silberbach GM, Kavanaugh-McHugh A, Cottrill C, Zhang Y, Riggs S, Smalls O, Johnson MC, Watson MS, Seidman JG, Seidman CE, Plowden J, Kugler JD. Mutations in the cardiac transcription factor NKX2.5 affect diverse cardiac developmental pathways. J Clin Invest 1999:104:1567-73

2 Schott JJ, Benson DW, Basson CT, Pease W, Silberbach GM, Moak JP, Maron BJ, Seidman CE, Seidman JG. Congenital heart disease caused by mutations in the transcription factor NKX2-5. Science 1998;281:108-11.

3 Krawczak M, Cooper DN. Gene deletions causing human genetic disease: mechanisms of mutagenesis and the role of the local DNA sequence environment. Hum Genet 1991;86:425-41

4 Lyons I, Parsons LM, Hartley L, Li R, Andrews JE, Robb L, Harvey RP. Myogenic and morphogenetic defects in the heart tubes of murine embryos lacking the homeo box gene Nkx2-5. Genes Dev 1995;9:1654-66

5 Kasahara H, Lee B, Schott JJ, Benson DW, Seidman JG, Seidman CE Izumo S. Loss of function and inhibitory effects of human CSX/NKX2.5 homeoprotein mutations associated with congenital heart disease. J Clin Invest 2000;106:299-308.

6 Patterson KD, Drysdale TA, Krieg PA. Embryonic origins of spleen asymmetry. Development 2000;127:167-75

7 Kasahara H, Bartunkova S, Schinke M, Tanaka M, Izumo S. Cardiac and extracardiac expression of $\mathrm{Csx} / \mathrm{Nkx} 2.5$ homeodomain protein. Circ Res 1998;82:936-46.

8 Kosaki K, Bassi MT, Kosaki R, Lewin M, Belmont J, Schaver G, Casey B. Characterization and mutation analysis of human LEFTY A and LEFTY $B$, homologues of murine genes implicated in left-right axis development. Am J Hum Genet 1999:64:712-21.

9 Gebbia M, Ferrero GB, Pilia G, Bassi MT, Aylsworth A, Penman-Splitt M, Bird LM, Bamforth JS, Burn J, Schlessinger D, Nelson DL, Casey B. X-linked situs abnormalities result from mutations in ZIC3. Nat Genet 1997; 17:305-8.

10 Meno C, Shimono A, Saijoh Y, Yashiro K, Mochida K, Ohishi S, Noji S, Kondoh $\mathrm{H}$, Hamada $\mathrm{H}$. lefty- 1 is required for left-right determination as a regulator of lefty-2 and nodal. Cell 1998;94:287-97

11 Campione M, Steinbeisser H, Schweickert A, Deissler K, van Bebber F, Lowe LA, Nowotschin S, Viebahn C, Haffter P, Kuehn MR, Blum M. The homeobox gene Pitx2: mediator of asymmetric left-right signaling in vertebrate heart and gut looping. Development 1999;126:1225-34

12 Shiratori H, Sakuma R, Watanabe M, Hashiguchi H, Mochida K, Sakai $Y$, Nishino J, Saijoh $Y$, Whitman $M$, Hamada $H$. Two-step regulation of left-right asymmetric expression of Pitx2: initiation by nodal signaling and maintenance by Nkx2. Mol Cell $2001 ; 7: 137-49$

13 Moore KL, Persaud TVN. The developing human clinically oriented embryology. 5th ed. Philadelphia: Saunders, 1993

14 Biben C, Weber R, Kesteven S, Stanley E, McDonald L, Elliott DA Barnett L, Koentgen F, Robb L, Feneley M, Harvey RP. Cardiac septal and valvular dysmorphogenesis in mice heterozygous for mutations in the homeobox gene Nkx2-5. Circ Res 2000;87:888-95. 